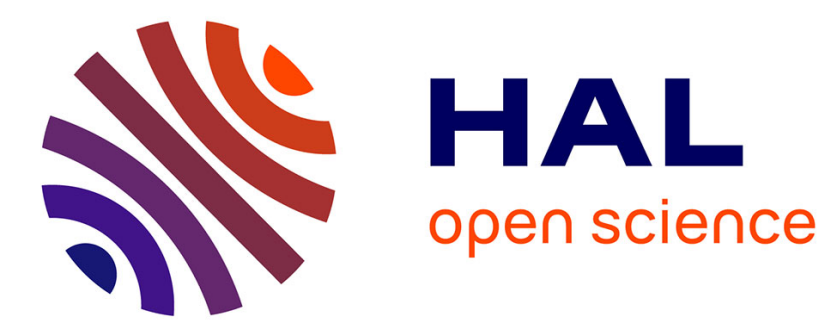

\title{
Democratization and Barriers to Entry in a Two-Dimensional Voting Model
}

\author{
Dmitry A. Veselov
}

\section{To cite this version:}

Dmitry A. Veselov. Democratization and Barriers to Entry in a Two-Dimensional Voting Model. 2015. halshs-01158139

\section{HAL Id: halshs-01158139 \\ https://shs.hal.science/halshs-01158139}

Submitted on 29 May 2015

HAL is a multi-disciplinary open access archive for the deposit and dissemination of scientific research documents, whether they are published or not. The documents may come from teaching and research institutions in France or abroad, or from public or private research centers.
L'archive ouverte pluridisciplinaire HAL, est destinée au dépôt et à la diffusion de documents scientifiques de niveau recherche, publiés ou non, émanant des établissements d'enseignement et de recherche français ou étrangers, des laboratoires publics ou privés. 


\section{Documents de Travail du

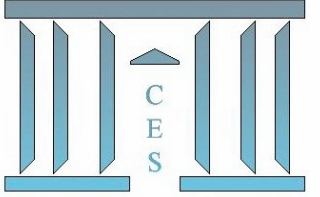

\section{Democratization and Barriers to Entry in a Two-Dimensional Voting Model}

Dmitry A. VESELOV

2015.04

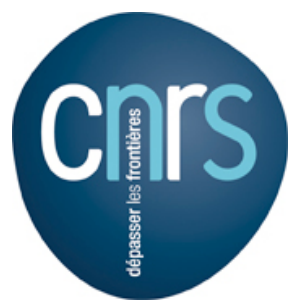

Maison des Sciences Économiques, 106-112 boulevard de L'Hôpital, 75647 Paris Cedex 13 


\title{
Democratization and Barriers to Entry in a Two-Dimensional Voting Model
}

\author{
Dmitry Veselov*
}

\begin{abstract}
We propose a simple quality-ladder model with heterogeneous agents differing in their skills and wealth endowment to explain the persistence of barriers to entry in new democracies. In the model agents vote for a rate of redistribution and for the level of barriers to entry, which protect the incumbent firms from competition with new entrants. We show that even if a society democratizes, under certain conditions this leads only to the rise of redistribution, rather than to the elimination of barriers to entry. We show that this argument is particularly relevant for countries with a low level of human capital and high inequality in incomes and in skills.

JEL Classification: O33, P16

Keywords: barriers to entry, majority voting, quality-ladders model, income inequality, skills inequality, persistence of economic institutions
\end{abstract}

\section{Introduction}

For the last thirty years a large group of countries in Latin America, East Asia and Eastern Europe have democratized their political regimes. Potentially this transition towards democracy could be a transition towards prosperity, if the diffusion of political power provides conditions for the wide support of inclusive economic institutions. At the same time, in many new democracies inefficient economic institutions usually persist.

The empirical evidence related to the effect of changes in political regimes from dictatorship to democracy on institutions and economic growth is contradictory. According to Barro (1996), democratization does not lead to higher economic growth and a study of Polterovich and Popov (2005) show that democratization even leads to lower growth in countries with poor institutions of law and order. According to Acemoglu et al.

* Laboratory of Macroeconomic Analysis, National Research University Higher School of Economics; dveselov@ hse.ru 
(2014) democratization does cause positive changes in GDP per capita, but only in the long run. They also find that the effect of democratization is stronger for countries which start out with higher levels of education.

One way to explain the effect of democratization on economic institutions and growth is to consider its effect on barriers to entry. Barriers to entry, which protect incumbents from competition with new entrants, is one of the form of economic institution which creates rent for narrow groups of agents at the costs of economic efficiency. Barriers to entry can be measured simply as costs of creating a new firm (Djankov et al., 2002). At the same time, a broader definition of barriers to entry includes also the differences in credit conditions, legal environment, property rights protection between incumbents and new entrants (Acemoglu, 2008).

In autocracies the costs of entry (creating a new business and dealing with licenses) are on average higher than in democracies (Djankov, 2008). At the same time, differences between de jure democratic countries are very high in terms of the costs of creating business or business environment. For example, South Korea and Argentina have been democratic countries since the end of 1980s according to Polity IV index, however, the place in the ranking of Doing Business Indicators (2012) is 8 for South Korea and 124 for Argentina (in Starting the business ranking, 8 and 154).

Acemoglu, Robinson (2008) explain the persistence of inefficient institutions in new democracies through the distribution of de facto political power. They introduce a notion of 'captured' democracy in which, despite the presence of de jure democratic political institutions, economic institutions remain extractive. According to their argument, at the onset of democratization political elites are capable of investing in alternative ways of influencing policy-making, that is lobbying, agenda manipulation etc. and, thus, make a strong opposition to the changes in economic institutions.

In this paper we propose a theoretical model which provides an alternative mechanism for the explanation of persistence of institutions which impede economic growth (in our case, the barriers to entry) and poor economic performance in new democracies. We show that even if de facto political power is distributed more equally under certain conditions the barriers to entry persist over time.

According to Schumpeter (1943) the central feature of democracy is political competition and the free entry of new parties into the political process. Polity IV database measures the level of democracy by estimating the competitiveness of state elections and their openness to outsiders as well as the existence of check and balances which prevent the concentration of political power. In our approach democracy is also a dictate of the majority. Political equilibrium is defined as majority core voting equilibrium (as, for example, in Fernándes, Rogerson (1995)), in which a stable coalition of agents choose the policy. All other agents, which do not belong to the stable majority coalition, do not influence social decision-making. Therefore, the difference between authoritarian regimes and democracy is simply the difference between the set of agents, which have the possibility to effect social choice. Democratization means also the extension of franchise and broader distribution of political power between agents. 
In a single-issue election with one-peaked voter preferences, if two parties compete for the majority of voters, then they optimally locate at the median voter (unique core point). At the same time, in a multi-issue election there is the problem of the intransitivity of majority preferences. To solve this problem, modern multi-dimensional voting models consider the institutional arrangements which restrict the possibilities of coalition formation and, thus, solve the problem of intransitivity of collective preferences (Levy, 2005, Fernández, Levy, 2008), or use probabilistic voting models (f.e. Bernasconi, Profeta, 2012). In our set-up we analyze the simple majority core voting equilibrium and do not restrict coalition formation. At the same time, following Krussell, Rios-Rull (1995), Parente, Zao (2006) we model the barriers to entry as a binary variable. We also restrict our attention to the one-period version of the model with agents maximizing their current pay-offs. Despite the presence of the cycling problem we show that in most cases a majority core voting equilibrium exists and is unique.

In our model a society consists of capitalists (shareholders of incumbent firms) and workers. Workers are heterogeneous in their human capital level. Some workers have also the entrepreneurial talent, which helps to organize new firms. Barriers to entry prevent the creation of new firms and, thus, permit incumbents to escape an $R \& D$ contest with new entrants. At the beginning of the period agents vote for the set of policies in a two-dimensional policy space, including the profit tax rate and the level of barriers to entry. The profit tax is collected from all firms and is redistributed to workers. In a free-entry regime as new firms carry the costs of investment in technological adoption there is a threshold level of profit tax rate, for which investments in new technology for them are profitable. We show that the policy preferences of high-skilled workers and low-skilled workers differ: high-skilled workers prefer zero entry barriers and relatively low redistribution rate, whereas low-skilled workers prefer high redistribution rate and high entry barriers. The shareholders of incumbent firms (capitalists) vote for the barriers to entry and zero redistribution rate.

The main result of the model is that democratization does not necessary lead to the elimination of barriers to entry. The high redistribution no-entry policy could be a stable political outcome supported by the majority consisting of the shareholders of incumbents firms (capitalists) and low-skilled workers. The political equilibrium is determined by the average skill level, de-facto political power distribution (the extent of democratization) and by the level of inequality in skills and pre-tax incomes. In an economy with a high average level of skills and low inequality of skills and income, all workers prefer zero barriers to entry and, hence, the democratization leads to zero entry barriers, enhances competition and growth.

The model explains the tendency towards the politics of populism in new democracies. Democratization can even lower growth if it does not lead to the changes in the economic institutions and only increases the redistribution, which is potentially distortionary. Our results also provide the theoretical basis for the empirical finding of Acemoglu et al. (2014) stating that the level of education influences positively the expected benefits from democratization. In the model the persistence of barriers to entry in new democracies is possible only for low skilled economies. 
The model is capable of explaining the phenomenon, according to which the middle class can be political outsiders. In the two-dimensional case, a higher rate of skill inequality increases the probability of coalition formation between the low-skilled workers and capitalists. The winning coalition does not include the middle class (high-skilled workers) and the equilibrium level of redistribution is determined by lower class agents. This fact explains the empirical finding of Scervini (2012) stating that the middle class does not play a decisive role in redistribution, as postulated by the median-voter hypothesis. Our analysis also shows that the rise in income inequality not only increases the preferences towards higher redistribution, but also decreases the political support for free-entry policy, as the gains from economic growth become distributed more unequally.

In Schumpeterian growth models (Aghion, Howitt, 1992, 1998) the patent system is a necessary institute for the existence of innovations and growth. In the case of the free copying of new technology potential innovators have zero interest to invest in new projects as the expected profits from these projects is always negative because of the free-rider problem. Therefore, patent protection is needed to assure a positive rate of innovations and growth. Here, we focus the barriers the in research sector. Barriers to entry in our model protect incumbent firms from a R\&D contest with new entrants, and hence, in some cases, discourage technological progress.

The paper is structured in the following way, section 2 describes the basic framework of the model, the innovation race between incumbents and new entrants and the effects of political choice on the results of this race. Section 3 describes types and preferences of agents, section 4 discusses the political equilibrium and the basic results. Section 5 analyzes several extensions of the baseline model, section 6 concludes.

\section{Basic framework}

The economy is inhabited by one-period lived agents, who maximize their current income. All agents are divided into $N$ capitalists and $L$ workers. Each capitalist is an owner of one incumbent firm, which produces an intermediate input from the final good. Each incumbent firm produces a unique version of an intermediate input and is a monopoly in its market and gets a profit $\pi$. Workers are employed only in the production of the final goods, which are produced in a competitive market using labor and intermediate inputs. The final good is used as a consumption good, as a raw material in the production of intermediate inputs and as an input in innovation activities ${ }^{1}$. Each worker supplies inelastically 1 unit of labor in a perfectly competitive labor market. Workers differ in the level of skills. The worker $k$ gets the wage $w h_{k}$, where $w$ is the wage rate per unit of skills and $h_{k}$ is the individual skills level. The distribution of skills is exogenous and constant over time.

\footnotetext{
${ }^{1}$ The general equilibrium framework of the model, which is similar to Howitt, Mayer-Foulke (2005) framework of schumpeterian growth model, is presented in Appendix A
} 
We assume that capitalists have no labor skills and so, they do not make an occupational choice, they only run incumbent firms. At the same time, a given number of workers have entrepreneurial skills, potential entrepreneurs have the capabilities to create new firms, producing intermediate inputs, and competing on the market with incumbent firms. For simplicity, we assume that workers with entrepreneurial skills are homogenous and so they have the same level of skills.

At the beginning of the period all agents make political decisions about the level of redistribution and the level of barriers to entry. The policy set is two-dimensional. In the political process a society chooses simultaneously the entry regime, to block the entry of new firms (B) or not to block $(N B)$ and a profit tax rate $\tau$, which provides the redistribution from capitalists to workers. All collected profit taxes are distributed between workers as lump-sum transfers.

After the elections, firms make investment decisions. The patent race between incumbents and new entrants is represented in figure 1 . Incumbent firms have the possibility to invest in $R \& D$ projects with a given rate of return. The rate of return on projects is the same between firms. By investing $c \pi$ units of final good ${ }^{2}$ the incumbent firm gets the profit $\gamma \pi(1-\tau)$ at the end of the period, where $\gamma 1, c$ are exogenous constants, measuring the size and costs of innovation and $\tau$ is the profit tax rate.

If incumbent firms do not invest in the projects, they risk being replaced by new entrants. For each sector there is one $e^{3}$ potential entrepreneur from the class of workers, who is able to invest in the same project with a given probability of success $\lambda \leq 1$, where $\lambda$ measures the level of entrepreneurial talents of potential innovators. We assume also that $\lambda$ is sufficiently high, such that the entry threat would be credible.

Assumption 1. $\lambda \gamma>\gamma-1$

If the new entrant is successful, the incumbent will loose the market in the competition with a new more efficient entrant. Incumbents have first-mover advantage, if they invest in the project, they are immune to competition.

As soon as investment projects are realized, firms produce goods and pay wages to workers. In order to limit the redistribution possibilities, we follow Acemoglu (2008) by supposing that firms can hide their profits from taxation. The costs of hiding is $\delta$ per unit of profits. This assumption guarantees that the actual tax rate does not exceed $\delta$, in the opposite case firms will hide profits and the total amount of tax incomes will drop to zero.

The timing of the model can be summarized in the following way:

\footnotetext{
${ }^{2}$ We assume here that the costs of innovations are proportional to the profit rate which is also proportional to the current complexity of innovation. The hypothesis that the costs of innovations rise proportionally to the complexity of innovations is typical for the qualityladders models. (f.e Aghion, Howitt (1998)) There is no credit market imperfections and projects are realized if their net present value is positive.

${ }^{3}$ The model can be easy extended for the case of multiple competitors. The results rest the same. The change of exogenous costs of innovations for entrepreneurs also does not alter the results.
} 
Figure 1: Patent race

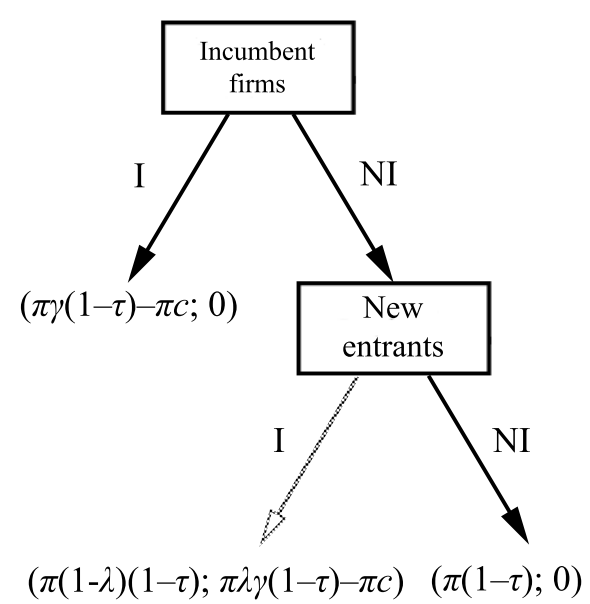

Note: The pay-off of incumbents and new entrants is represented in round brackets. Investments can be positive (I) or zero (NI). The white arrow underlines the fact that new entrants are capable of making investments only in the NB-regime.

1. The entry regime $(B, N B)$ and a tax rate $\tau$ are chosen in the political process. This decision is not renegotiable;

2. A patent race between incumbents and new entrants occurs;

3. Firms produce goods and pay wages;

4. All producers decide whether to hide profits;

5. Redistribution and consumption occurs.

Definition 1. Economic equilibrium. Given the policy variables (the entry regime and the tax rate, $\tau$ ) the economic equilibrium is a sequence of investment decisions of incumbent firms and potential entrants and a hiding decision of firms, as well as wage rate ( $w)$, profit rate $(\pi)$ and transfer payments $(\mathrm{Tr})$, such that all firms maximize their after-tax profits and market clearing conditions for the labor market, the intermediate input markets and the final goods market hold. The budget constraint is balanced (the sum of tax payments equals the sum of transfer payments).

In Appendix A we show that in an economic equilibrium the wage rate and profit rate are proportional to the size of technology, which is measured by the average quality of intermediate products. We also show that if investment projects are realized the quality of intermediate inputs increases by $\gamma$ and income per capita, profits and wages increases also by $\gamma$. This is a standard result for Schumpeterian growth models. Let's find now the equilibrium investment decision of incumbent firms and new entrants, given the policy variables. 
In the economic equilibrium investment decisions of incumbent firms depend on the pre-tax rate of return on projects, which is determined by the exogenous costs and the size of innovations $(c, \gamma)$ and the policy variables (the entry regime, the tax rate). In a patent race game (fig. 2) as soon as the following inequality holds

$$
\gamma(1-\tau)-c \geq 1-\tau
$$

the rate of return on investments is so high, that incumbent firms will invest in the project even in the Bregime. In this case the type of the entry regime does not influence the economic outcomes (fig.2, area 1). In the opposite case two scenarios are possible. Either the entry threat is credible or not. If the expected profits for new entrants are negative

$$
\lambda \gamma(1-\tau)-c<0
$$

even in the free-entry case the entry threat is not credible. The investment rate is zero as incumbent firms also do not make investments (fig.2, area 3). If the entry threat is credible (fig.2, area 2), incumbents always will use their first mover advantage and invest in projects, to avoid the possibility of being replaced by the new entrant (escape competition effect) ${ }^{4}$. To show this, let us compare the expected profits of incumbent firms in the case when the entry threat is credible. Incumbent firms will use their first mover advantage, if

$$
\gamma(1-\tau)-c \geq(1-\lambda)(1-\tau)
$$

As soon as the entry threat is credible, $c<\lambda \gamma(1-\tau)$. Under this constraint, the inequality (3) always holds ${ }^{5}$

Figure 2 describes three economic equilibria of the model. In the areas 1 and 3 the entry regime does not effect the investment level. In the area 2, incumbents make investments only in the NB-regime to escape competition with new entrants. We assume that $\lambda \gamma>\gamma-1$ and so, the probability of innovations for new entrants is sufficiently high such that the area 2 is not an empty set. In the opposite case, the entry regime will not have any influence on firms decisions and the political problem will reduce to a one-dimensional case of distributional conflict.

The rise of the profit tax rate decreases the expected rate of return of investment and could influence the firms incentives to invest. Let define $\tau^{\prime}$ as the threshold rate of profit tax: if $\tau>\tau^{\prime}$ new entrants do not

\footnotetext{
${ }^{4}$ Aghion et al.(2007) show that increased competition even lowers the incentives for innovation for firms, which lag behind the technological frontier. For these firms the presence of new more efficient entrants decreases the potential rent from the new innovation. We do not consider this effect in this model as we concentrate our attention to the formation of the entry barriers. Even if incumbent firms lag behind they will also oppose the policy, which eliminates the barriers to entry, which is consistent with our model

${ }^{5}$ One can argue that investment costs of research projects are different for incumbent firms and new entrants. In this case different scenarios are possible. If the research costs for new entrants are relatively high, only incumbent firms have incentives to invest, therefore, the political problem becomes one-dimensional as the entry regime does not effect the firms' economic decisions. If the research costs for new entrants are relatively low than the research costs of incumbent firms, potential entrants are very efficient relative to incumbents, which will not use their first mover advantage in the patent race. This case is considered in the complement paper, Veselov (2013)
} 
Figure 2: Economic equilibrium

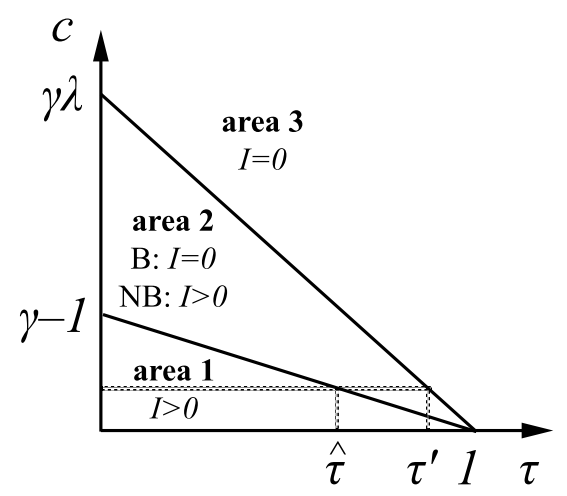

Note: The entry regime effects the investment rate only in the area 2

invest in new projects even if barriers to entry are absent. From (2)

$$
\tau^{\prime}=1-c / \lambda \gamma
$$

We also define the threshold tax rate $\widehat{\tau}$, such that for $\tau<\widehat{\tau}$ the incumbent firms make investment even in the B-regime. From (1)

$$
\widehat{\tau}=1-c /(\gamma-1)
$$

By assumption $\widehat{\tau}$ is always less than $\tau^{\prime}$ and so, the policy problem is two-dimensional.

\subsection{Agents political preferences}

Now we specify the agents political preferences in a two-dimensional policy space $\left\{J, \tau_{J}\right\}$, where $J \in$ $\{B, N B\}, \tau_{B} \in[0,1], \tau_{N B} \in\left[0, \tau^{\prime}\right]$. These preferences determine the political behavior of agents and the endogenous choice of policy variables, which will be specified in the next section. We define the NB-regime as the regime with zero entry barriers and also the credible entry threat $\left(\tau \leq \tau^{\prime}\right)$.

\subsubsection{Capitalists' preferences}

The capitalists' pay-off consists of the after-tax profits of incumbent firms, which are distributed to capitalists as dividends. Capitalists pay-off in the B-regime equals

$$
V_{c}^{B}=\max \{(1-\tau) \pi ;[\gamma(1-\tau)-c] \pi\}
$$


In the B-regime incumbent firms freely chose whether to invest in the project or not and the capitalists pay-off is the highest possible gain from these two alternatives. In the NB-regime incumbent firms always use their first-mover advantage and invest in projects. Therefore, the capitalists' pay-off in the NB-regime equals

$$
V_{c}^{N B}=[\gamma(1-\tau)-c] \pi
$$

The formulas (6), (7) hold for $\tau \leq \delta$. If $\tau>\delta$ the incumbent firms will hide profits and the capitalists' pay-off will be the same as in the case of $\tau=\delta$.

Figures 3, 4 describe the capitalists pay-offs in the B- and NB-regimes for different level of profit tax $(\tau)$. If the rate of return on projects is relatively low, such that $c>\gamma-1$, (fig.3), the B-regime is always better for capitalists, than the NB-regime. As soon as the entry threat is credible, incumbent firms will invest in the project only to escape competition and so they get lower profits, than in the B-regime.

Figure 3: Capitalists pay-off if $c>\gamma-1$ and $\tau^{\prime}<\delta$

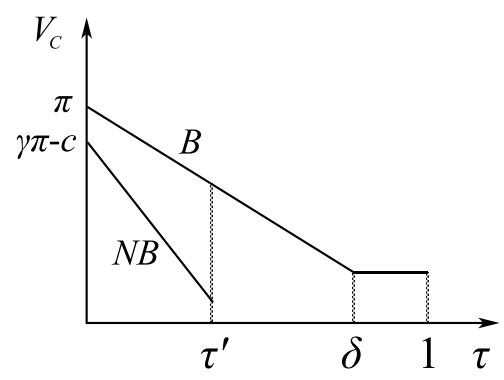

If the rate of return on projects is sufficiently high $c<\gamma-1$ (fig. 4) for a low tax rate $\tau \leq \widehat{\tau}$ capitalists are indifferent between the two entry regimes, as in both regimes incumbent firms will invest in the project and get the same level of profits. For $\tau>\widehat{\tau}$ the capitalists prefer the B-regime.

Figure 4: Capitalists pay-off if $\gamma>1+c, \widehat{\tau}<\tau^{\prime}<\delta$

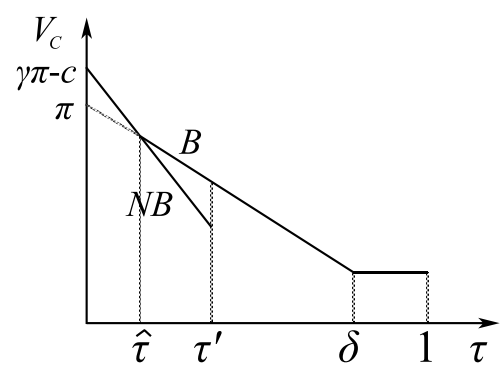

In all cases capitalists bliss-point is (B,0). They are indifferent between (NB,0) and (B, 0$)$ if $\tau \leq \widehat{\tau}$. 


\subsubsection{Workers' preferences}

The workers pay-off consists of wages and the lump-sum transfers. For $\tau<\delta$ the firms do not hide their profits and the lump-sum transfers for each worker equal $\tau \pi N / L$. If incumbent firms do not invest in new projects (the B regime with $\tau>\widehat{\tau}$ ) workers pay-off $\left(V_{k}^{N I}\right)$ equals

$$
V_{k}^{N I}=w h_{k}+\tau \pi N / L
$$

In the B- and NB-regime with $\tau \leq \widehat{\tau}$, investment projects are realized and wages, profits and transfer payments increase proportionally by $\gamma^{6}$. Therefore, the workers pay-offs $V_{k}^{I}$ equal

$$
V_{k}^{I}=\gamma\left[w h_{k}+\tau \pi N / L\right]
$$

We assume that the distribution of levels of skills is fixed and workers are not capable of changing their individual skills level. Higher skilled workers get higher salaries, but also benefit more from the technological progress. Therefore, there is a potential disagreement between the high-skilled workers and low-skilled workers, who consider the transfer payments as the main source of income. The formal analysis of this claim is presented in Proposition 1.

Let define $\bar{h}$ as the average level of human capital within workers, and $\alpha$ is the ratio of total profits to total wages.

$$
\alpha=\pi N /(w \bar{h} L)
$$

The next proposition follows

Proposition 1. Workers bliss points

1. For high rate of return $c<\lambda(\gamma-\delta)$ all workers prefer the NB-regime with the highest possible redistribution rate $\tau=\min \left\{\tau^{\prime}, \delta\right\}$.

2. For intermediate rate of return $\lambda(\gamma-\delta)<c<\lambda \gamma$ the bliss point for the group of relatively high skilled workers with $h_{k} \geq h^{\prime}$ is $\left(N B, \tau^{\prime}\right)$, for the rest of workers $\left(h_{k}<h^{\prime}\right)$ the bliss point is $(B, \delta)$, where

$$
h^{\prime}=\bar{h} \alpha(\delta-\gamma+c / \lambda) /(\gamma-1)
$$

3. For low rate of return $(c>\lambda \gamma)$ the entry is not possible and all workers prefer the maximum redistribution rate $(B, \delta)$.

Proof. If $\tau^{\prime} \geq \delta$ it is straightforward to see that all workers prefer maximum possible redistribution rate $\delta$ and the NB-regime. If $\tau^{\prime}<\delta$ there is a trade-off between the free-entry regime with a lower redistribution

\footnotetext{
${ }^{6}$ see Appendix A for the explanation of this result in the general equilibrium set-up
} 
rate and the no-entry regime with a high redistribution rate. The bliss point for workers is either $\left(\mathrm{NB}, \tau^{\prime}\right)$ or $(B, \delta)$. Let us compare the workers pay-off in each case. From (8) and (9)

$$
\begin{gathered}
V_{k}\left(N B, \tau^{\prime}\right)=\gamma\left[w h_{k}+\tau^{\prime} \pi N / L\right], \\
V_{k}(B, \delta)=w h_{k}+\delta \pi N / L
\end{gathered}
$$

Workers prefer $\left(N B, \tau^{\prime}\right)$ policy only if

$$
\gamma\left[w h_{k}+\tau^{\prime} \pi N / L\right]>w h_{k}+\delta \pi N / L
$$

Dividing the inequality (14) by $w \bar{h}$ we get

$$
\gamma\left[h_{k} / \bar{h}+\tau^{\prime} \alpha\right]>h_{k} / \bar{h}+\delta \alpha .
$$

The inequality (15) can be represented as

$$
(\gamma-1) h_{k} / \bar{h}>\left(\delta-\tau^{\prime} \gamma\right) \alpha
$$

Substituting $\tau^{\prime}$ to the equation (16) we get

$$
(\gamma-1) h_{k} / \bar{h}>(\delta-\gamma+c / \lambda) \alpha
$$

For $c<\lambda(\gamma-\delta)$ the inequality (17) holds for every positive $h_{k}$. For $c>\lambda \gamma$ the investment rate is always zero and all workers prefer the maximum redistribution policy. In the intermediate case there is a threshold level of human capital $h^{\prime}$, which divides agents into two groups, the first one $\left(h<h^{\prime}\right)$ prefers B-regime with high redistribution rate $\delta$ and the second $\left(h \geq h^{\prime}\right)$ prefers $\left(\mathrm{NB}, \tau^{\prime}\right)$ policy.

The result of proposition 1 is illustrated in figures 5, 6. We define two groups of workers of a size $L_{1}, L_{2}$, with the identical within-group bliss points. As soon as the net gains from technological progress concentrate mostly in the hands of firm-owners and high-skilled workers, the group of relatively low-skilled workers $\left(L_{1}\right)$ prefers the B-regime with the maximum redistribution rate. The group of relatively skilled workers $\left(L_{2}\right)$ prefer a lower rate of redistribution and the free-entry regime with positive investments.

The size of both groups depends on the skills distribution between workers. From (17) the more skewed the human capital distribution is, the higher the number of supporters of the B-regime between workers. A higher share of wages in total revenues (lower $\alpha$ ) decreases the gain from redistribution, but increases the gain from economic growth for all workers, and, finally, increases the number of supporters of the NBregime between workers. The rate of return of projects also matters. A higher $\gamma$ or lower $c$ also increases the 
Figure 5: Low skilled workers $\left(L_{1}\right)$ pay-off, $h_{k}<h^{\prime}$

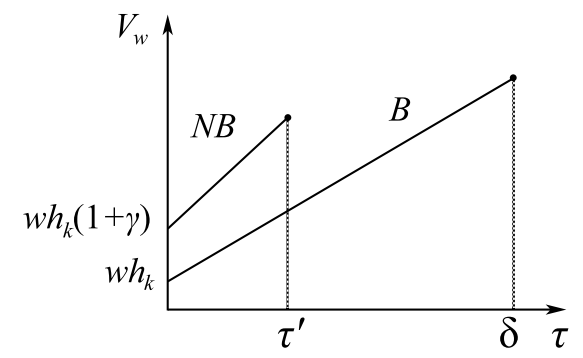

Figure 6: High-skilled workers $\left(L_{2}\right)$ pay-off, $h_{k}>h^{\prime}$

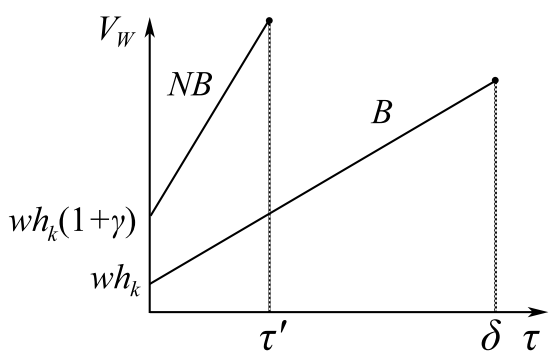

number of workers, supporting the free-entry regime.

\section{Political equilibrium}

In this section we study how political regimes influence the economic behaviour of agents. The main goal is to analyze the effect of democratization on political and economic outcomes. A perfect democracy is a political regime, in which de facto political power is equalized between all agents. The total number of votes, therefore, equals $N \beta+L$. By de facto political power we mean the number of real votes belonging to each agent. Let $\beta$ measure de facto political power of capitalists, such that each capitalist has $\beta$ votes, $\beta \geq 1$. Democratization in this case leads to the extension of the franchise to workers as their relative number of votes increases. If $\beta=1$ each agent has one vote, which is a perfect democracy case. For $\beta>L / N$ capitalists are decisive voters and a political regime is an oligarchy ${ }^{7}$

\footnotetext{
${ }^{7}$ The question, which is beyond the scope of this analysis, is the question about endogenous democratization. Acemoglu, Robinson (2005) proposed a game-theoretical approach for analysis of democratization process. In their view, inequality in incomes and redistribution conflict between poor and rich stimulate the poor agents to strife for democracy. In their model elites deliberately chose democratization to avoid revolution and also to solve a dynamic inconsistency problem. If democratization does not happen, there is no device to commit credibly redistribution in future
} 
Definition 2. Majority core voting equilibrium. A political equilibrium is a combination of an entry regime $J^{*}=\{B, N B\}$ and a tax rate, such that there is no a strict majority of voters, who prefer another feasible combination $\left\{J, \tau_{J}\right\}$ to $J^{*}$.

During the transition to democracy political power diffuses to larger group of voters, therefore, capitalists loose the dominant political power $\beta<L / N$ and, by definition of political equilibrium, in order to influence policy outcomes they need to form a stable winning coalition with workers. A potential effect of democratization on barriers to entry, redistribution and investments is summarized below

\section{Case 1. One-dimensional conflict.}

1.1. The highest rate of return $(c<\gamma-1)$.

In this case all workers prefer the NB-regime with a maximum possible redistribution rate ( $\delta$ for $\delta<\tau^{\prime}$, or $\tau^{\prime}$ in the opposite case). The highest rate of return guarantees that even in an oligarchy incumbent firms make investments. Democratization results in more redistribution, but does not influence the investment rate, which is positive for both regimes.

This case describes democratization in growth-miracle countries, especially in East Asian countries like South Korea or Japan. At the beginning of a take-off even authoritarian regimes in these countries were characterized by high growth rates. The transition to democracy does not have a large influence on growth rates and business environment indicators.

2.2. The lowest rate of return, $c>\lambda \gamma$.

This is a poverty trap case, even a decrease in barriers to entry does not provide incentives to invest in projects. All workers prefer $(B, \delta)$ policy and all capitalists prefer $(B, 0)$ policy. There is a one-dimensional distributional conflict between capitalists and workers. This case describes the democratization process in the least-developed countries, which is usually connected with redistribution of wealth and incomes without any specific changes of economic institutions.

\section{Case 2: Two-dimensional conflict.}

The policy space is two dimensional for an intermediate level of a rate of return $\gamma-1<c<\lambda \gamma$. In this case two scenarios of democratization are possible. In the first one changes of political institutions lead to the elimination of entry barriers. If $c<\lambda(\gamma-\delta)$ all workers have an identical bliss-point $\left(N B, \tau^{\prime}\right)$ and the transition to democracy induces the transformation of the entry regime, which influences positively the investment rate, while capitalists prefers $(B, 0)$ regime. A new democracy is consolidated in the sense that there is no conflict of interest within workers. Even if a democratic regime is imperfect, and each capitalist

has larger de facto political power, than an individual worker, workers constitute an encompassing majority which have a dominant political power. 
However, for $c>\lambda(\gamma-\delta)$ there are already three groups of agents with different bliss-points: capitalists prefer $(B, 0)$ policy, relatively high-skilled workers prefer $\left(N B, \tau^{\prime}\right)$ and relatively low-skilled workers prefer $(B, \delta)$. Under these conditions there is a second possibility of democratization, which is related to populism ${ }^{8}$.

As soon as there is a disagreement between workers relative to their preferred policy a majority coalition under certain conditions include the richest group of society (capitalists) and the poorest group of society (low-skilled workers). This claim is formally proved in the next proposition.

Let us define $h_{k m}$ as the level of skills of the worker who simultaneously belongs to a minimum majority coalition of capitalists and the least-skilled workers, and also has a maximum level of skills within the members of this coalition.

Proposition 2. Let consider the case, when $L_{1}, L_{2}, \beta N$ is less than one half of the voters. Three political outcomes are possible.

a) $\{B, \delta\}$ is a majority core equilibrium, which is supported by the coalition of capitalists and the leastskilled workers. This happens if the distribution of skills is highly skewed, democratization is partial and the ratio of total profits to total wages $(\alpha)$ is sufficiently high such that the following inequality holds

$$
(\gamma-1) h_{k m} / \bar{h} \alpha<1+c-\gamma
$$

and $\delta \in\left(\delta_{1}, \delta_{2}\right), \delta_{1}=(\gamma-1) h_{k m} / \bar{h}+\gamma \tau^{\prime}, \delta_{2}=1+c+c / \lambda$

b) There is no a stable equilibrium if condition (18) holds and $\delta>\delta_{2}$.

c) In all other cases $\left\{N B, \tau^{\prime}\right\}$ is a majority core equilibrium.

Proof. see Appendix B

In most of the cases the political equilibrium exists and is unique. From the proposition 2, there exists a simple condition which guarantees the existence and the uniqueness of political equilibrium

$$
\delta<\lambda \gamma+1-\gamma
$$

In the case of three groups of voters, If $\delta$ is high, such that the condition (19) is violated, each majority coalition of voters is unstable. We assume that the inequality (19) holds, therefore, the political equilibrium always exists. Figure 7 summarizes an equilibrium political outcome iwhich depends of the type of political regime and the rate of return on projects. From proposition 2 we find conditions, under which democratization does not effect barriers to entry and only leads to a rise of redistribution.

\footnotetext{
${ }^{8}$ We define populism as a policy, which does not eliminate the barriers for entry ans does not promote a rise of incomes, but reduces an income inequality through redistribution. In this set-up there is a trade-off between inequality and growth and a social optimum depends on a type of social preferences as well as relative weights of inequality and incomes in the social preferences. Thus, populistic policies sacrifices growth to promote equality and can be in some cases an efficient policy
} 
Figure 7: The political equilibria

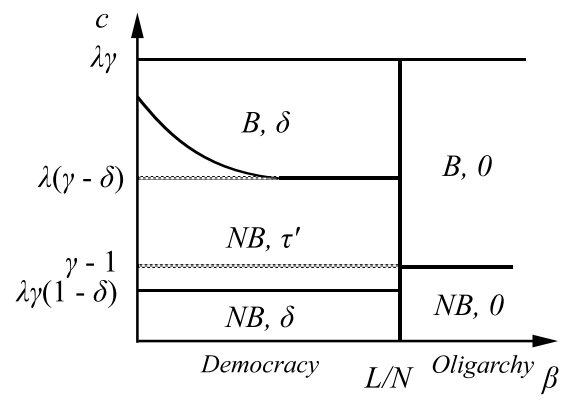

Note: For $c<\lambda(\gamma-\delta)$ all workers prefer the NB-regime. For $\lambda(\gamma-\delta)<c<\lambda \gamma$ there is a conflict of interest within workers. The area $(B, \delta)$ becomes larger, if skills distribution between workers becomes more unequal or a share of capitalists income in total revenue increases

We show at the end of Appendix A that the costs of the project $(c)$ are negatively related with the average level of skills, which is exogenous in our model. In the next corollary, we consider only the effect of changes in the level of skills, other things equal

Corollary 1. It exists a threshold average skills level $\left(\bar{h}^{*}\right)$, such that in an economy with high-skilled labor force $\left(\bar{h} \geq \bar{h}^{*}\right)$ democratization always leads to the elimination of barriers to entry, in an economy with low-skilled labor force $\left(\bar{h}<\bar{h}^{*}\right)$ barriers to entry remain persistent if 1) democratization is only partial or 2) the inequality in human capital distribution is high or 3) the relative share of wages in total income is low.

To clarify this result let us consider a numerical example in which there is no consensus within workers and so, the level of average human capital is sufficiently low. Suppose that, the distribution of human capital between workers is approximated by the log-normal distribution. We set $\gamma=1.5, \lambda=0.8, c=0.78$, assuring that $\tau^{\prime}=0.35$. We set also $\delta=0.6$ and $\alpha=1 / 2$. The ratio of the number of capitalists to the number of workers (N/L) equals 1/10. Figure 8 describes political outcomes depending on two main factors, the type of political regime $(\beta)$ and the level of inequality in skills, which is measured by the ratio of an average level of skills to the median level of skills $\left(\bar{h} / h_{m e d}\right)$.

A partial democratization leads to the formation of a coalition between capitalists and the lowest skilled workers (area $L_{1}+N$ ). Capitalists in this case agree to the maximum redistribution of profits $(\delta)$ to avoid competition of incumbents firms with new entrants. Low-skilled workers also support this policy, as they prefer to vote for the maximum redistribution, rather then to support low-redistribution, free-entry case. Even in a perfect democracy the NB-regime is not realized in the political equilibrium if an inequality of skills or an inequality of pre-tax incomes between capitalists and workers is sufficiently high. One implication of this result is that, as soon as a coalition of capitalists and low-skilled workers if formed, an equilibrium level of redistribution is chosen by poor, rather than by middle class agents. 
Figure 8: Majority coalitions and political outcomes in the case of different workers preferences (numerical example)

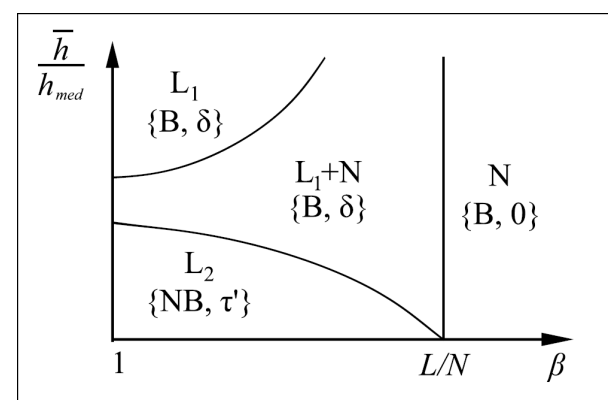

\section{Extensions}

In this section we check the robustness of results to the changes of several assumptions. Firstly, an imperfect commitment case is considered. We also analyze a model with heterogeneous projects, which provides a smooth effect of an increase in the tax rate on investment rates and economic growth.

\subsection{Imperfect commitment case}

One of the assumptions of the model is that a majority coalition gives a credible commitment do not change the profit tax rate $(\tau)$ after the realization of all projects. There is a dynamic inconsistency problem: as soon as investment projects are realized, the majority, consisting of all workers, prefer to set the maximum tax rate $(\delta)$. Suppose now that there is a positive probability $\rho$ that the tax rate will be reconsidered in the end of the period. Thus, the model has the following timing:

1. the entry regime (B,NB) and a tax rate $\tau$ are chosen in the political process;

2. A patent race between incumbents and new entrants occurs;

3. Firms produce goods and pay wages;

4. The profit tax rate is revised by the majority of agents with a probability $\rho$;

5. All producers decide whether to hide profits;

6. The redistribution and consumption occurs.

As soon as investment projects are realized all workers prefer to chose the maximum redistribution rate $(\delta)$. Therefore, an expected profit tax rate for firms equals

$$
\tau^{e}=\tau_{a n}(1-\rho)+\rho \delta
$$


where $\tau_{a n}$ is the announced tax rate at the beginning of the period. New entrants invest in new projects only if

$$
\lambda \gamma\left(1-\tau^{e}\right)-c \geq 0
$$

From (20) and (21) the announced threshold level of taxes is redefined as

$$
\tau_{a n}^{\prime}=[1-c /(\lambda \gamma)-\rho \delta] /(1-\rho)
$$

As soon as the commitment to set a low tax rate is imperfect a majority coalition has to announce a lower level of tax rate, than in the base-line model, in order to guarantee that the expected tax rate will not exceed the threshold level. For high $\rho$, such that

$$
\rho>[1-c /(\lambda \gamma)] / \delta
$$

$\tau_{a n}^{\prime}$ becomes negative and so, the expected tax rate is so high that the NB-regime does not exist at all. The NB-regime exists only if

$$
c \leq \lambda \gamma(1-\rho \delta)
$$

The preferences of capitalists and workers, regarding to the entry regime and the tax rate $\tau^{e}$ rest unchanged. Therefore, if condition (24) holds the results of the previous analysis of political equilibrium also do not change. In the opposite case, the democratization does not lead to the elimination of the entry barriers, as the politics of a low tax rate are not credible.

\subsection{The case of heterogeneous investment projects}

In the previous analysis we assume that all investment projects are identical. Therefore, there is a threshold tax rate $\tau^{\prime}$ which is the same for all projects, such that for higher tax rate investments become zero. In this subsection we consider the case, when the projects have the different rate of return, and so, the rise in the tax rate will decrease the number of existing investment project, and lowers the future economic growth rates, but not drastically. This case is more realistic, but also is more complex for analysis.

Let suppose now that incumbents firms differ in their profit level. The incumbent firm $i$ gets a profit $\pi(i)$. The costs of investment $c(i)$ also differ across industries and are distributed uniformly between $\left[0, c_{\max }\right]$. For the purpose of tractability, we assume that the innovation project costs differ between industries, but not within industries. That means, that incumbents and new entrants face the same $c(i)$ in the identical sector.

The timing of the model is as follows:

- Agents make political decisions about the level of entry barriers and the profit tax rate. We assume that 
this decision cannot be renegotiated during the current period.

- The information about the research costs $c(i)$ is revealed for each industry,

- Incumbent firms make investment decisions,

- Potential entrants make investment decisions,

- Investment projects are realized,

- All producers make a decision whether to hide profits at the costs $\delta \pi(i)$,

- The redistribution and consumption occurs.

In the B-regime potential entrants are absent and incumbents invest in the new project only if the net gain from this investment is positive. In the one-period model the net gain from the project is simply the expected profit at the end of the period minus the costs of the project.

$$
\gamma(1-\tau)-c(i) \geq 1-\tau
$$

Rearranging the items, we get the threshold level of project costs $\left(c^{B}\right)$. If $c(i) \leq c^{B}$ the incumbent makes investments the in B-regime, where

$$
c^{B}=(\gamma-1)(1-\tau) .
$$

In the NB-regime new entrants invest in projects only if incumbents chose not to invest and if

$$
\lambda \gamma(1-\tau)-c(i) \geq 0
$$

Therefore, there is another threshold rate of the costs of the projects $\left(c^{N B}\right)$, such that for $c(i)<c^{N B}$ new entrants make investment in new projects. As previously, we assume that

$$
\lambda>1-1 / \gamma
$$

and so $c^{B} \leq c^{N B}$. Therefore, barriers to entry influence firm behavior in industries with intermediate costs $c^{B} \leq c(i) \leq c^{N B}$. As in the basic model, in the NB-regime incumbents always use their first-mover advantage to invest in projects. The income per capita growth is equal to the technological progress growth rate. Initially all industries are symmetric, after the innovation profits and value added increase by $\gamma$. For uniform distribution of innovation costs from 0 to $c_{\max }$ the expected growth rates for each regime of barriers to entry is determined as

$$
g_{a}^{B}=(\gamma-1)^{2}(1-\tau) / c_{\max }
$$

and

$$
g_{a}^{N B}=(\gamma-1) \gamma \lambda(1-\tau) / c_{\max }
$$


The crucial feature of this version of the model is that the profit tax rate impedes innovations in both economic regimes. This is the traditional distortional effect of redistribution (Person, Tabellini (1992)). The higher tax rate decreases economic growth as it lowers the private benefits from innovation activities and so leads to a drop in innovation efforts. At the same time, from assumption 1 it follows that given the tax rate the NBregime is more pro-growth $g_{a}^{N B}>g_{a}^{B}$, as the elimination of barriers to entry stimulate innovations through the competition effect.

Let us now determine agents pay-offs in the two-dimensional policy space $\left\{J, \tau_{J}\right\}$, where $J \in$ $\{B, N B\}, \tau_{J} \in[0,1]$.

The capitalists' expected pay-off in the B-regime equals

$$
V_{c}^{B}=\left(\int_{0}^{c^{B}}[\gamma(1-\tau)-c(i)] \pi d c(i)+\int_{c^{B}}^{c_{\max }}[(1-\tau) \pi] d c(i)\right) / c_{\max }
$$

After calculations we get

$$
V_{c}^{B}=\pi\left(1-\tau+(\gamma-1)^{2}(1-\tau)^{2} /\left(2 c_{\max }\right)\right)
$$

Capitalists expected pay-off in the NB-regime equals:

$$
V_{c}^{N B}=\left(\int_{0}^{c^{N B}}[\gamma(1-\tau)-c(i)] \pi d c(i)+\int_{c^{N B}}^{c_{\max }}[(1-\tau) \pi] d c(i)\right) / c_{\max }
$$

(33) can be represented as

$$
V_{c}^{N B}=\pi\left[1-\tau+\lambda \gamma(1-\tau)^{2}(\gamma / 2-1) / c_{\max }\right]
$$

From (32),(34) for the given tax rate capitalists always prefer the B-regime to the NB-regime. Only for $\tau=1$ capitalists are indifferent between two regimes. The bliss point for the capitalists is $(B, 0)$.

Worker pay-offs depend on their individual skills level $\left(h_{k}\right)$. Let $b$ be a Boolean variable which equals $\gamma-1$ in B-regime and $\lambda \gamma$ in NB-regime. Then for a sub-group $k$, the workers payoff equals

$$
V_{k}=w h_{k}\left[1+(\gamma-1) b(1-\tau) / c_{\max }\right]+T r
$$

where $\operatorname{Tr}=\tau \pi\left(1+(\gamma-1) b(1-\tau) / c_{\max }\right) N / L$ for $\tau \leq \delta$ and equals zero for $\tau>\delta$. As output increases by a factor of $\gamma$ in the NB-regime, wage, tax collection and transfer payments also increase by the same size. The next proposition follows:

Proposition 3. 1) For the given tax rate $\tau$ all workers prefer the NB-regime to the B-regime.

2) For the given entry regime workers preferences are single-peaked in the one-dimensional tax space.

3) In the B-regime workers become more pro-redistributive. That is, for each worker $j$ given the entry regime 
there are two bliss points, $\left(B, \tau_{j}^{B}\right)$ and $\left(N B, \tau_{j}^{N B}\right)$ and $\tau_{j}^{B} \geq \tau_{j}^{N B}$.

Proof. The proposition follows directly from the properties of the pay-off function (35). In the NB-regime for the given tax rate, the increase in competition leads to a higher rate of investment in new projects and increases workers pay-off through the effect on economic growth rates. The function $V_{w}(\tau)$ has one global maximum $\tau_{j}^{*}$, and is increasing for $\tau<\tau_{j}^{*}$ and is decreasing for $\tau>\tau_{j}^{*}$. The level $\tau_{j}^{*}$ depends on the parameters of the model, such as the relative skills of worker $j$, the size of innovations and the ratio of total profits to total wages $(\alpha)$.

All workers prefer the NB-regime to the B-regime as the free entry regime enhances competition and provides a higher pace of technological adoption, and, hence, a growth in wages. At the same time, low skilled workers have smaller gains from the high pace of innovation, therefore, they prefer a no-entry high redistribution regime to the free-entry low-redistribution case. As in the baseline model capitalists can also prefer the no-entry regime with high-redistribution rate to the free-entry regime with low redistribution rate.

Proposition 4. In the model with heterogeneous firms if $\beta<L / N$ there are two possible scenarios 1) The majority core voting equilibrium $\left(N B, \tau_{\text {median }}^{N B}\right)$ exists and unique. This is the NB-regime with the tax rate, which is proffered by the median voter.

2) The majority core voting equilibrium does not exist because of the cycling problem.

Proof. Let's define $\tau_{N B}^{*}$ as the tax rate which is supported by the median voter in the NB-regime. Now we can find the conditions under which $\left(N B, \tau_{N B}^{*}\right)$ is the majority core voting equilibrium. As the preferences of all agents are single-peaked in one-dimensional policy space of rate of taxes From the median voter theorem there is no other policy $\left(N B, \tau_{N B}\right)$, which will be preferred by the majority of votes. At the same time, the policy $\left(B, \tau_{B}\right)$ with a higher tax rate could be supported by a majority coalition of low skilled workers and capitalists. If it is true the stability conditions will not be satisfied. The $\left(B, \tau_{B}\right)$ is always worse, than $\left(N B, \tau_{B}\right)$ for all workers, and the policy $\left(N B, \tau_{B}\right)$ will always worse, than $\left(N B, \tau_{N B}^{*}\right)$ for the majority of workers from the median voter theorem. Therefore, there is a cycling problem and no equilibria exists in this case.

In the model with heterogeneous firms the same factors influence the existence and stability of freeentry equilibrium in democracy. If the human capital level is sufficiently low and human capital distribution is highly skewed the free-entry equilibrium becomes unstable as low-skilled workers and capitalists will vote for a no-entry equilibrium with a high redistribution rate. At the same time, in the heterogeneous project case, the no-entry equilibria with high redistribution rate is unstable, and we need to add additional restrictions on the process of coalition formation to guarantee the stability of the no-entry equilibrium. 


\section{Conclusion}

In this chapter we show that more equal distribution of political rights does not obviously lead to the suppression of barriers to entry. If voters chose both the level of redistribution and the barriers to entry democratization always leads to an increase in income redistribution, however, it decreases entry barriers in goods markets only under certain conditions, which includes a high average level of skills, a low inequality in pre-tax income between capitalists and workers and a low inequality of skills between workers. Under these conditions there is a majority of voters, which consists of all workers, supporting a free-entry regime. Democratization in countries with a low initial level of education and high inequality in wealth and skills results in the populistic policies, supporting by the coalition of capitalists and low-skilled workers. In this case, the middle class consisting of high-skilled workers becomes a political outsider. This argument is particularly relevant for countries with deep historical roots of wealth inequality and inequality of opportunities, as well as for countries relying on the export of natural resources.

One argument, that we do not consider in our baseline model, is the possibility of the endogenous choice of education policies. Saint-Paul, Verdier (1992) show that democracy can provide redistribution in the form of education subsidies, which are beneficial for economic growth. In our view, a final result will depend on the effect of the education policy on the inequality of incomes within workers. If the gain from education subsidies will be concentrated in the hands of the middle class (like in Fernández and Rogerson (1995), Veselov (2012)) a winning coalition of capitalists and low-skilled workers will be stable. Moreover, a change in skills distribution is a long process, and, therefore, the benefits from the education policy could be provided only in the long-run.

\section{Acknowledgments}

I am particularly grateful to Fuad Aleskerov and to Antoine D'Autume for valuable comments and suggestions. I would like to thank Victor Polterovich, Jean-Pierre Laffargue, Stéphane Rossignol, Allan Drazen, Eren Arbatli, Nikolay Arefiev, Alexandr Yarkin for their valuable comments. I am indebted to the participants of Inequo and Dynamic methods seminars in the Paris-1 Panthéon Sorbonne University, the Mathematical Economics seminar in the Russian Academy of Science, Society of Social Choice and Welfare 2014 conference and ASSET 2014 conference for the discussion of this study. The study was implemented in the framework of the Basic Research Program at the National Research University Higher School of Economics in 2014 


\section{Appendix A. The general equilibrium set-up}

Let us consider a quality-ladders model, which is based on the model of Howitt and Mayer-Foulkes (2005). Assume that there is a single general good, produced by labor and specialized intermediate inputs, according to the following production function

$$
Y=(H / N)^{1-\alpha} \sum_{0}^{N} A(i)^{1-\alpha} x(i)^{\alpha} .
$$

where $Y$ is the output of the general good, $H$ is the quantity of skill-adjusted labor engaged in production and $x(i)$ is the quantity of intermediate input $i, A(i)$ is the current quality of intermediate input $i, N$ measures the number of intermediate inputs, and $1-\alpha$ is the share of labor income in the total output of the general good. The general good can be used interchangeably as consumption or an input in intermediate goods production or R\&D input ${ }^{9}$. Producers of the general good are perfect competitors on all markets, so the equilibrium price of intermediate inputs $p_{x}(i)$ is equals to the marginal product in producing the general good

$$
p_{x}(i)=\alpha A(i)^{1-\alpha}(H / N)^{1-\alpha} x(i)^{\alpha-1} .
$$

We assume that the production of each particular type of intermediate inputs is performed by an unconstrained monopolistic firm ${ }^{10}$ that uses one unit of the general good to produce one unit of input. Thus a monopolistic firm maximizes its profit by choosing the level of production of intermediate inputs

$$
\max \left\{p_{x}(i) x(i)-x(i)\right\}
$$

In this case from the monopolist problem the equilibrium price is equal to

$$
p_{x}(i)=1 / \alpha
$$

From equations (37) and (39) the equilibrium quantity $x(i)$ equals

$$
x(i)=\alpha^{2 / 1-\alpha} A(i) H / N .
$$

Substituting equation (40) into (36) we obtain the equilibrium output of the general good

$$
Y=\alpha^{\frac{2 \alpha}{1-\alpha}} A H,
$$

\footnotetext{
${ }^{9}$ For this type of the production function the number of varieties of intermediate inputs (N) does not influence workers productivity because of the increased specialization effect. A higher number of varieties increases the specialization costs, which eliminate the positive direct effect on the output (see f.e. Bucci, 2009)

${ }^{10}$ The alternative assumption about the competitive fringe in each intermediate input sector does not influence the results
} 
where $A$ is the average quality of intermediate inputs engaged in production. Therefore, the growth rate of the final output per capita equals the rate of technological progress, which is measured by the average quality of intermediate inputs plus the rate of human capital accumulation. From (39) and (40) the level of profit for each monopolist equals

$$
\pi(i)=(1-\alpha) \alpha^{\frac{1+\alpha}{1-\alpha}} A(i) H .
$$

The level of profits is proportional to the aggregate level of skills and to the level of technology. In a competitive labor market the wage rate equals the marginal product of labor

$$
w=\alpha^{2 \alpha /(1-\alpha)} A
$$

The equilibrium output of the general good can be divided by wages, monopolistic profits and inputs in the intermediate goods production sector

$$
Y=w H+\sum_{0}^{N}[\pi(i)+x(i)] .
$$

where $w$ is skill-adjusted wage rate. At the same time, from (36), (42), (43) the shares of wages and profits in the final output are constant

$$
\begin{gathered}
w H=(1-\alpha) Y, \\
\sum_{i=0}^{N} \pi(i)=\alpha(1-\alpha) Y,
\end{gathered}
$$

and the ratio of total profits to total wages equals $\alpha$. The wage rate per unit of skills, and profits is proportional to the level of technology. The rise of the level of technology by $\gamma$ increases by the same size the wages and profits. In the baseline model the costs of the investment project in terms of the general good is proportional to the current level of technology, $c^{\prime} A(i)$, where $c^{\prime}>0$. From (42) we redefine the costs of the project as $c \pi(i)$, where

$$
c=c^{\prime} N /\left(H(1-\alpha) \alpha^{\frac{1+\alpha}{1-\alpha}}\right) .
$$

Therefore, a higher level of average skills $(\bar{h}=H / L)$ leads to a decrease of the relative costs of the project (c).

\section{Appendix B. Proof of the Proposition 2}

1) If $c<\lambda \gamma(1-\delta)$, then, by the definition of $\tau^{\prime}, \tau^{\prime}>\delta$ and all workers prefer $(N B, \delta)$, which is a stable political outcome. 
2.1) For $\tau^{\prime}<\delta$ let us check firstly if $\left(N B, \tau^{\prime}\right)$ is a political equilibrium or not. All workers always prefer $\left(N B, \tau^{\prime}\right)$ to the $\left(N B, \tau<\tau^{\prime}\right)$ and $\left(B, \tau<\tau^{\prime}\right)$. Thus, the only other potential policy that could be supported by the majority of voters is $\left(B, \tau>\tau^{\prime}\right)$. As $\left(N B, \tau^{\prime}\right)$ is a bliss point for relatively high skilled workers, only capitalists and low-skilled workers could form a coalition to overcome $\left(N B, \tau^{\prime}\right)$. This is the case if

$$
\left\{\begin{array}{l}
\tau_{B} \leq \delta \\
V_{c}\left\{N B, \tau^{\prime}\right\}<V_{c}\left\{B, \tau_{B}\right\} \\
V_{k m}\left\{N B, \tau^{\prime}\right\}<V_{k m}\left\{B, \tau_{B}\right\},
\end{array}\right.
$$

where $\mathrm{km}$ is a sub-group of workers who have a maximum level of skills and at the same time belong to the majority coalition of low-skilled workers with capitalists.

(48) is rewritten as

$$
\left\{\begin{array}{l}
\tau_{B}<\delta \\
\left(1-\tau_{B}\right)>\gamma\left(1-\tau^{\prime}\right)-c \\
w h_{k m}+\tau_{B} \pi N / L>\gamma\left[w h_{k m}+\pi N \tau^{\prime} / L\right]
\end{array}\right.
$$

Dividing both sides of the last inequality by $w \bar{h}$ we rewrite the system (49) as

$$
\left\{\begin{array}{l}
\tau_{B}<\delta \\
\tau_{B}<1+c-\gamma\left(1-\tau^{\prime}\right) \\
\tau_{B}>h_{k m}(\gamma-1) /(\bar{h} \alpha)+\gamma \tau^{\prime}
\end{array}\right.
$$

From (50) there is a policy $\left(B, \tau_{B}\right)$, which is strictly preferred to $\left(N B, \tau^{\prime}\right)$ by the majority, consisting of capitalists and low-skilled workers, only if the following conditions are satisfied

$$
\left\{\begin{array}{l}
h_{k m}(\gamma-1) /(\bar{h} \alpha)+\gamma \tau^{\prime}<\delta \\
h_{k m}(\gamma-1) /(\bar{h} \alpha)<1+c-\gamma
\end{array}\right.
$$

Therefore, only for $\delta>\delta_{1}$ and condition (18) $\left(N B, \tau^{\prime}\right)$ is not majority core voting equilibrium. Let us note that if (18) holds it is straightforward to see that $\delta_{1}$ is always lesser than $\delta_{2}$.

2.2) Let us prove now that if (18) holds and if $\delta>\delta_{2}$, then a majority core equilibrium does not exist. If (18) holds, $\left(N B, \tau^{\prime}\right)$ is always dominated by $\left(B, \tau_{B}>\tau^{\prime}\right)$, where $\tau_{B}$ satisfies (23). At the same time from 
(50) $\tau_{B}<\delta_{2}<\delta$. In this case $(B, \delta)$ is always preferable to $\left(B, \tau_{B}<\delta\right)$ by all workers. However, from the pay-offs definition $\left(N B, \tau^{\prime}\right)$ is better than $\left(B, \delta>\delta_{2}\right)$ for the majority consisting of high-skilled workers and capitalists. Thus, there is a cycling problem and no stable political equilibrium exists.

2.3) Let us show that if (50) does not hold the majority core voting equilibrium $\left(N B, \tau^{\prime}\right)$ is unique. The policy $\left(J, \tau<\tau^{\prime}\right)$ cannot be a political equilibrium as all workers strictly prefer $\left(N B, \tau^{\natural}\right)$. The policy $\left(B, \tau_{B}>\tau^{\natural}\right)$ is not also an equilibrium as, as soon as the conditions (50) are not satisfied, there is always a strict majority of voters among workers, who strictly prefer $\left(N B, \tau^{\natural}\right)$.

\section{References}

1. Acemoglu D. Robinson J.A.,2005. Economic origins of dictatorship and democracy. Cambridge University Press.

2. Acemoglu, D., 2008, Oligarchic versus democratic societies. Journal of the European Economic Association 6(1), 1-44.

3. Acemoglu D. Robinson J.A.,2008, Persistence of Power, Elite and Institutions. American Economic Review, 98:1, 267-293

4. Acemoglu D., Naidu S., Restrepo P., Robinson J.F., 2014, Democracy does Cause Growth. NBER Working Paper 20004.

5. Alesina A.,Rodrik D. 1994. Distributive Politics and Economic Growth. The Quarterly Journal of Economics. 1994. Vol. 1.02. No 2. . 465-490.

6. Aghion, P., Howitt P, 1998. Endogenous growth theory. The MIT press.

7. Aghion, P., Alesina A., and Trebbi F. 2007. Democracy, technology, and growth, June, National Bureau of Economic Research, Inc.

8. Barro. R. 1996. Democracy and growth. Journal of Economic Growth. 1. 1-27.

9. Bernasconi M., Profeta P. 2012. Public education and redistribution when talents are mismatched. European Economic Review 56 (2012) 84-96

10. Bucci A. 2011. Product varieties, Population, Competition and Growth. DEGIT Conference Papers c016_006.

11. Djankov S., La Porta R., Lopez-De-Silanes F. Shleifer A., 2002. The Regulation Of Entry. The Quarterly Journal of Economics, MIT Press, vol. 117(1), pages 1-37, February. 
12. Djankov, S, 2008. The Regulation of Entry: A Survey. CEPR Discussion Papers 7080, C.E.P.R. Discussion Papers

13. Fernández R., Rogerson R. 1995. On the Political-Economy of Education Subsidies. Review of Economic Studies. 62(2). pp. 249-62

14. Fernández R., Levy G. Diversity and Redistribution. Journal of Public Economics 92 (2008) 925-943.

15. Howitt, P., Mayer-Foulkes D., 2005, R\&d, implementation, and stagnation: A schumpeterian theory of convergence clubs, Journal of Money, Credit and Banking 37(1), 147-177.

16. Krusell, Per, and Jose-Victor Rios-Rull, 1996, Vested interests in a positive theory of stagnation and growth, Review of Economic Studies 63(2), 301-329.

17. Levy G. 2005. The politics of public provision of education. Quarterly Journal of Economics, 120(4), $1507-1534$.

18. McKelvey R.D., Wendell R.E. 1976. Voting Equilibria in Multidimensional Choice Spaces. Mathematics of Operational Research. Vol.1. No.2. pp. 144-157

19. Meltzer, A. H., and S. F. Richard, 1981, A rational theory of the size of government, Journal of Political Economy 89(5), 914-927.

20. Polterovich V. Popov V. 2005. Democracy and Growth Reconsidered: Why Economic Performance of New Democracies is not Encouraging. MPRA paper 21606

21. Parente, S.L., and R. Zhao. 2006. Slow development and special interests. International Economic Review 47:991-1011.

22. Prescott, E. C., and S. L. Parente, 1999, Monopoly rights: A barrier to riches, American Economic Review 89(5), 1216-1233.

23. Persson T. and G. Tabellini. 1994. Is Inequality Harmful for Growth. The American Economic Review Vol. 84, No. 3 (Jun.), pp. 600-621

24. Saint-Paul G. Verdier T. 1992. Education, Democracy and Growth Journal of Development Economics. 42. pp. 399-407.

25. Schumpeter I. 1943. Capitalism, Socialism and Democracy. Edition published in the Taylor Francis e-Library in 2003.

26. Scervini F. 2012. Empirics of the median voter: democracy, redistribution and the role of the middle class. Journal of Economic Inequality. 10:529-550

27. Veselov D.A. 2012. Political Equilibrium and Social Optimum in the Economy with Two Types of Redistribution. HSE Economic Journal. 2012. . 16. 3. C. 341 - 367 
28. Veselov D. A. 2013. Redistribution and the political support of free entry policy in the Schumpeterian model with heterogenous agents / Working papers by Centre d'Economie de la Sorbonne. Series cesdoc:13050 "Documents de travail du Centre d'Economie de la Sorbonne". No. 2013.50 